\title{
FEAR AND DEPRESSION AMONG RESIDENTS OF BOSNIA AND HERZEGOVINA DURING COVID-19 OUTBREAK - INTERNET SURVEY
}

\author{
Armin Šljivo ${ }^{1}$, Majda Kačamaković ${ }^{1}$, Iman Quraishi ${ }^{1}$ \& Alma Džubur Kulenović ${ }^{2}$ \\ ${ }^{I}$ Medical student, Faculty of Medicine, University of Sarajevo, Sarajevo, Bosnia and Hercegovina \\ ${ }^{2}$ Department of Psychiatry, Clinical Center of University of Sarajevo, University of Sarajevo, \\ Sarajevo, Bosnia and Hercegovina
}

received: 28.4.2020;

revised: 15.5.2020;

accepted: 22.5 .2020

\begin{abstract}
SUMMARY
Background: Occurrence of symptoms of fear and depression among general population during the outbreak of COVID-19 seems to present an emerging problem worldwide. The aim of this study was to examine levels of fear and depressive symptoms in association with COVID-19 outbreak and to assess other contributing factors in the population of Bosnia and Herzegovina.

Subjects and methods: Link to an anonymous questionnaire, mainly based on The Fear of COVID-19 Scale (Ahorsu et al. 2020) and two-item and nine-item Patient Health Questionnaires (PHQs) (Maurer et al. 2018) (background information, fear assessment and information regarding depression) was distributed online to general population of Bosnia and Herzegovina.

Results: Out of 1201 respondents, 217 (18.0\%) reported experiencing fear and 341 (28.4\%) reported having symptoms of depression during COVID-19 outbreak. The mean age of the subjects was 30.57士11.26. Being older (OR=1.044; 95\% CI 1.031-1.057; $p<0.001)$ and having moderate to severe depressive symptoms $(O R=1.093 ; 95 \%$ CI 1.067-1.120; $p<0.001)$ were independent significant predictors for developing fear; living in rural environment (OR=0.551; 95\% Cl 0.325-0.935; $p=0.0027)$ significantly decreased the risk of developing fear; being female (OR=1.750; 95\% CI 1.242-2.466; $p=0.001)$, unemployed $(O R=1.557 ; 95 \%$ CI 1.040-2.330; $p=0.032)$ or student $(O R=1.943 ; 95 \%$ CI 1.450-2.604; $p<0.001)$ were independent significant predictors for developing moderate to severe depressive symptoms in association with COVID-19. Mann Whitney U-test showed that being older was statistically associated with fear $(p<0.001)$ and being younger was statistically associated with depressive symptoms $(p<0.001)$.

Conclusions: In conclusion, based on our findings, fear and depressive symptoms in general population of Bosnia and Herzegovina during the outbreak of COVID-19 were present in $18.06 \%$ (fear) and $28.39 \%$ (depression) of subjects and it was statistically associated with age, gender, occupation, living environment and may present a secondary uprising problem connected to outbreak of COVID-19
\end{abstract}

Key words: fear - depressive symptoms - pandemics - COVID-19

\section{INTRODUCTION}

In December 2019, the world was startled by an outbreak of a novel coronavirus, officially named SARS$\mathrm{CoV}-2$ (Wu et al. 2020) which firstly occurred in Wuhan City, China and soon afterwards spread worldwide leading to a pandemic ( $\mathrm{Zu}$ et al. 2020, Marčinko et al. 2020). Most patients with SARS-CoV-2 infection present with mild flu-like symptoms such as fever, cough, myalgia, dyspnea (Huang et al. 2020) and pharyngeal erythema in children ( $\mathrm{Lu}$ et al. 2020), while only few patients rapidly develop acute respiratory distress syndrome, shock, acute kidney or cardiac failure (Lui et al. 2020) or even death (Epidemiology Working Group for NCIP Epidemic Response, Chinese Center for Disease Control and Prevention 2020). Human-tohuman transmission of SARS-CoV-2 occurs via droplets, respiratory secretions (Guo et al. 2020) and direct contact, mainly between family members, relatives and friends and first helpers who closely contact with patients or infective carriers ( $\mathrm{Li}$ et al. 2020).

The first case of coronavirus disease (COVID-19) in Bosnia and Herzegovina was reported on March $5^{\text {th }}$
2020 (JZU institut za javno zdravstvo Republike Srpske 2020) and from that point some unprecedented epidemiologic measures, including closing of public spaces, limiting movement of the population, curfew, suspension of public transportation, closing borders for foreigners, mandatory quarantine for $\mathrm{B} \& \mathrm{H}$ nationals returning to the country, and limiting working hours of essential services, grocery stores, restaurants etc with closing down of non-essential services, have been adopted to control the transmission of COVID-19 in the country (Federalni štab civilne zaštite FBIH. Bosna i Hercegovina 2020, Vlada Republike Srpske 2020).

At the same time when governments and health agencies were trying to identify modes of transmission, strategies for disease containment and treatment for COVID-19, general fear of dying or getting in contact with individuals who are possibly infected is spreading throughout the global community and has already been reported. (Lin 2020, Ćosić et al. 2020). In such situation of mass threat, the level of fear is directly associated with the transmission rate and medium (rapidly and invisibly) as well as morbidity and mortality of the infectious disease (Ahorsu et al. 2020). This phenomenon, 
described both as protective and harmful (Espinola et al. 2016), further leads to other psychosocial challenges including stigmatization and discrimination towards people infected with or affected by the infectious disease which delays seeking appropriate medical care and thus may lead to further spreading of the disease (Pappas et al. 2009). Furthermore, fear is further fueled by restrictions imposed through epidemiological measures that are set to maintain virus spread and mandatory practices such as quarantine and isolation. In general, high level of fear may amplify the damage of the disease itself and individuals' thinking and emotional processing may be affected by reaction to COVID-19 (Ahorsu et al. 2020).

The other aspect of this crisis is caused by protective measures imposed by the civil authorities, centers for disease control and various health agencies where we would particularly like to highlight social isolation. Social isolation may lead to lack of everyday social interactions. This presents further challenge to individual's coping strategies where the use of maladaptive coping strategies may contribute to increasing symptoms such as fear, anxiety (Shuja et al. 2020) and depressive symptoms. Studies show that prolonged social isolation and loneliness increase the risk for development of depression among the general population (Matthews et al. 2016, Ge et al. 2017). This phenomenon could be further amplified by concerns about and personal, family and community wellbeing issues (Zuelke et al. 2018, Drakulić \& Radman 2020) due to pending economic crisis caused by the pandemics and lead to further contribute to the occurrence of symptoms.

One more factor worth mentioning is the infodemics aspect of the COVID-19 pandemics through the media and social networks pertaining (Jakovljević 2020) both to the disease and to possible sociological and political consequences of the present situation (fear of the rise of totalitarian systems, societal and political control and obstruction of personal freedom).

The aim of this study was to examine levels of fear and depressive symptoms in association with COVID-19 outbreak in Bosnia and Herzegovina and to assess other contributing factors to development of these phenomena in the population of Bosnia and Herzegovina.

\section{SUBJECTS AND METHODS}

\section{Subjects}

This cross-sectional study was conducted in the period between April $7^{\text {th }}$ and $12^{\text {th }} 2020$ among general population of Bosnia and Herzegovina. Exclusion criteria were (i) not being a citizen of Bosnia and Herzegovina and (ii) being already infected with COVID-19 and (iii) being younger than 18 years. Subjects completed an anonymous online questionnaire based on a The COVID-19 Fear Scale (Ahorsu et al. 2020) and Patient Health Questionnaires (Maurer et al. 2018). The questionnaire was translated to $\mathrm{B} / \mathrm{C} / \mathrm{S}$ language and distribu- ted to subjects via Facebook profiles and groups. The respondents completed the questionnaire on a voluntary and anonymous basis. The questionnaire was open for 5 days and it yielded 1.213 responses.

\section{Study instrument and data collection}

Questions in the questionnaire were divided into three sections, as follows: 1. demographic information which included age, gender, marital status, education, occupation, and place of current residence; 2. measurement of fear of COVID-19 and 3. severity of depression symptoms. Fear was measured using The Fear of COVID-19 Scale (FCV-19S). (Ahorsu et al. 2020) Subjects indicated their level of agreement with seven statements using a five-item Likert-type scale ("strongly disagree," (1 point) "disagree," (2 points) "neither agree nor disagree," (3 points) "agree," (4 points) and "strongly agree" (5 points)). A total score ranged from 7 to 35 with higher score indicating greater fear of COVID-19. To check the reliability of the FCV-19S (to be more specific, its internal consistency), Cronbach alpha coefficient was calculated. Its value was $\alpha=0.880 \quad(n=7)$ indicating a very good internal consistency of the scale.

Depressive symptoms were measured using Patient Health Questionnaires, PHQ-2 and PHQ-9. (Maurer et al. 2018) If either one out of questions on PHQ-2 was positive, 9-item PHQ-9 was administered in order to assess the severity of the depressive symptoms. Total score of PHQ-9 ranged from 0 to 27 with score $<5$ indicating not likely to be depressed, score 5-9 indicating mild depressive symptoms, score 10-14 indicating moderate depressive symptoms, score 15-19 indicating moderately severe depressive symptoms and score 20-27 indicating severe depressive symptoms. Cronbach alpha coefficient, calculated for the PHQ-2 and PHQ-9 taken together was $\alpha=0.892(n=11)$ which indicated a high level of their internal consistency.

It took approximately 5 to 10 minutes to complete the questionnaire.

\section{Statistical analysis}

Collected data were analyzed using software "Statistical Package for the Social Sciences (SPSS) version 20.0. (IBM, 2020). In order to summarize the data, descriptive statistics was performed. The results for categorical variables were presented in frequencies and percentages and for numerical variables by mean \pm standard deviation for normally distributed data, or by median $\left(25^{\text {th }} ; 75^{\text {th }}\right.$ quartile $)$ for not normally distributed data. Chi square test $\left(\chi^{2}\right)$ was conducted to test associations between different categorical variables and Mann Whitney U test to test association between different variables. Binary logistic regression was conducted to determine independent predictors for development of fear and depressive symptoms during the COVID-19 outbreak. 


\section{RESULTS}

In total, 1.213 subjects completed the questionnaire. 12 subjects were excluded from the study because of the exclusion criteria. The final sample consisted of 1.201 subjects.

\section{Background information}

943 subjects were female $(78.5 \%)$, and the remaining $21.5 \%$ were male. The mean age was $30.57 \pm 11.26$ and it ranged from 18 to 78 . Most of the respondents were students $526(43.8 \%)$, followed by non-manual workers 449 (37.4\%), unemployed 169 (14.1\%) and manual workers 57 (4.7\%). The majority $1113(92.7 \%)$ did not experience any changes in their employment status from the beginning of the crisis. Marital status, education level and other background information of subjects are displayed in the Table 1.

\section{Fear and COVID-19}

Out of 1.201 subjects, 217 (18.1\%) subjects reported having strong fear associated with COVID-19. Of all patients that reported fear, most of them were female $186(85.7 \%)$, single $112(51.6 \%)$, either students 81 $(37.3 \%)$ or non-manual workers $87(40.1 \%)$ and living in urban environment 198 (91.2\%). Association of gender, education level, current occupation, marital status and living environment are presented in Table 1. Other feelings and attitudes towards COVID-19 reported from subjects with fear are presented in Table 2 .

When age and score of FCV-19S were compared between subjects who reported fear with subjects who didn't report fear, a statistical significance was found. (median 31.0 vs 25.0; $\mathrm{U}=82830.5 ; \mathrm{p}<0.001$ ); (median 22.0 vs 14.0; $U=23017.0 ; \mathrm{p}<0.001)$. Subjects with fear were significantly older and scored higher on FCV-19S than those who didn't report fear.

Independent predictors for development of fear in association with COVID-19 were identified with binary logistic regression and displayed in Table 3.

\section{Depression and COVID-19}

Out of $1.201,341(28.4 \%)$ subjects tested positive for moderate to severe depressive symptoms, 314 (26.1\%) were placed on a watchful list and had mild depressive symptoms and $546(45.5 \%)$ tested negative. Subjects with moderate to severe depressive symptoms were mostly females 291 (85.3\%), single 235 (68.9\%), students $181(53.1 \%)$ and living in urban environment 290 $(85.0 \%)$. Differences between groups of subjects who tested positive for moderate to severe depressive symptoms and those who didn't in association with various factors are displayed in Table 1 . The majority of subjects $229(67.1 \%)$ associated their moderate to severe depressive symptoms with current COVID-19 pandemic. Severity of depression in association with gender, age, education, occupation and living environment in comparison with subjects who tested negative for depressive symptoms is displayed in Table 4.

Out of all subjects with moderate to severe depressive symptoms, $38(11.2 \%)$ (28 (8.2\%) subjects with severe depression, $5(1.4 \%)$ with moderately severe depression and $5(1.4 \%)$ with moderate depression) reported self-injuring or having suicidal ideas almost every day.

Table 1. Gender, education level, occupation, marital status and living environment of subjects with and without fear and with and without depressive symptoms

\begin{tabular}{|c|c|c|c|c|}
\hline Variables & $\begin{array}{l}\text { Subjects without fear } \\
\qquad N=984\end{array}$ & $\begin{array}{l}\text { Subjects with fear } \\
\qquad N=217\end{array}$ & $\begin{array}{c}\text { Subjects without } \\
\text { depressive symptoms } \\
\mathrm{N}=546\end{array}$ & $\begin{array}{c}\text { Subjects with } \\
\text { depressive symptoms } \\
\mathrm{N}=341\end{array}$ \\
\hline \multicolumn{5}{|l|}{ Gender } \\
\hline female & $757(80.3 \%)$ & $186(19.7 \%)$ & $413(58.7 \%)$ & $291(41.3 \%)$ \\
\hline male & $227(88.0 \%)$ & $31(12.0 \%)$ & $133(72.7 \%)$ & $50(27.3 \%)$ \\
\hline \multicolumn{5}{|l|}{ Education level } \\
\hline high school & $437(83.9 \%)$ & $84(16.1 \%)$ & $237(59.2 \%)$ & $163(40.8 \%)$ \\
\hline bachelor degree & $284(79.3 \%)$ & $74(20.7 \%)$ & $141(59.0 \%)$ & $103(41.0 \%)$ \\
\hline masters degree & $210(81.1 \%)$ & $49(18.9 \%)$ & $132(68.4 \%)$ & $61(31.6 \%)$ \\
\hline $\mathrm{PhD}$ & $53(84.1 \%)$ & $10(15.9 \%)$ & $36(72.0 \%)$ & $14(28.0 \%)$ \\
\hline \multicolumn{5}{|l|}{ Occupation } \\
\hline student & $445(84.6 \%)$ & $81(15.4 \%)$ & $191(51.3 \%)$ & $181(48.7 \%)$ \\
\hline non-manual worker & $362(80.6 \%)$ & $87(19.4 \%)$ & $250(72.9 \%)$ & $93(27.1 \%)$ \\
\hline manual worker & $47(82.4 \%)$ & $10(17.6 \%)$ & $25(61.0 \%)$ & $16(39.0 \%)$ \\
\hline unemployed & $130(76.9 \%)$ & $39(23.1 \%)$ & $80(61.1 \%)$ & $51(38.9 \%)$ \\
\hline \multicolumn{5}{|l|}{ Marital status } \\
\hline single & $625(84.8 \%)$ & $112(15.2 \%)$ & $291(55.3 \%)$ & $235(44.7 \%)$ \\
\hline married & $323(77.3 \%)$ & $95(22.7 \%)$ & $226(71.5 \%)$ & $90(28.5 \%)$ \\
\hline divorced & $36(78.3 \%)$ & $10(11.7 \%)$ & $21(56.7 \%)$ & $16(43.3 \%)$ \\
\hline \multicolumn{5}{|l|}{ Living environment } \\
\hline urban & $831(80.7 \%)$ & $198(19.3 \%)$ & $471(61.9 \%)$ & $290(38.1 \%)$ \\
\hline rural & $153(88.9 \%)$ & $19(11.1 \%)$ & $75(59.5 \%)$ & $51(40.5 \%)$ \\
\hline
\end{tabular}


Table 2. Feelings and attitudes towards COVID-19 reported from subjects with fear

Variable

Subjects with fear $\mathrm{N}=217$

It makes me uncomfortable to think about Coronavirus-19

Strongly agree

Agree

Neither agree or disagree

Disagree

Strongly disagree

My hands become clammy when I think about Coronavirus-19

Strongly agree

Agree

Neither agree or disagree

Disagree

Strongly disagree

$$
\begin{gathered}
69(31.8 \%) \\
116(53.4 \%) \\
27(12.4 \%) \\
3(1.4 \%) \\
2(0.9 \%) \\
\\
9(4.1 \%) \\
22(10.1 \%) \\
51(23.5 \%) \\
64(29.5 \%) \\
71(33.6 \%) \\
\\
44(20.3 \%) \\
71(32.7 \%) \\
55(25.3 \%) \\
30(13.8 \%) \\
17(7.8 \%)
\end{gathered}
$$

I am afraid of losing my life because of Coronavirus-19

Strongly agree

Agree

Neither agree or disagree

Disagree

Strongly disagree

When watching news and stories about Coronavirus-19 on social media, I

become nervous or anxious

Strongly agree

Agree

Neither agree or disagree

Disagree

Strongly disagree

I cannot sleep because I'm worrying about getting Coronavirus-19

Strongly agree

Agree

Neither agree or disagree

Disagree

Strongly disagree

\begin{tabular}{|c|c|c|c|}
\hline Independent predictors & Odds ration & $95 \% \mathrm{CI}$ & p-value \\
\hline \multicolumn{4}{|l|}{ Fear in association with COVID-19 } \\
\hline Older age & 1.044 & $1.031-1.057$ & $<0.001$ \\
\hline Rural environment & 0.551 & $0.325-0.935$ & 0.027 \\
\hline Moderate to severe depressive symptoms & 1.093 & $1.067-1.120$ & $<0.001$ \\
\hline \multicolumn{4}{|c|}{$\begin{array}{l}\text { The model was not statistically significant } \chi^{2}=4.514, p=0.808 \text {; it explained } 12.3 \% \text { (Nagelkerke } R 2 \text { ) } \\
\text { and correctly classified } 82.5 \% \text { of cases. }\end{array}$} \\
\hline \multicolumn{4}{|l|}{ Depression in association with COVID-19 } \\
\hline Female & 1.750 & $1.242-2.466$ & 0,001 \\
\hline Unemployed & 1.557 & $1.040-2.330$ & 0.032 \\
\hline Student & 1.943 & $1.450-2.604$ & $<0.001$ \\
\hline Manual worker & 1.534 & $0.821-2.856$ & 0.180 \\
\hline $\begin{array}{l}\text { The model was not statistically significant } \chi^{2}= \\
\text { and correctly classified } 71.5 \% \text { of cases }\end{array}$ & explained 4.1 & lkerke R2) & \\
\hline
\end{tabular}

My heart races or palpitates when I think about getting Coronavirus-19

Strongly agree

Agree

Neither agree or disagree

Disagree

Table 3. Binary logistic regression model for identification of independent predictors for development of fear and moderate to severe depressive symptoms in association with COVID-19 
Table 4. Severity of depression in association with gender, age, education, occupation and living environment in comparison with subjects who tested negative for depressive symptoms

Variables

\section{Subjects without}

depressive

symptoms $\mathrm{N}=546$
Subjects with moderate to severe depressive symptoms $\mathrm{N}=341$

Moderate depressive Moderately severe symptoms depressive symptoms

$\mathrm{N}=211$ $\mathrm{N}=75$

$26.65 \pm 8.43$

$62(21.3 \%)$

$13(26.0 \%)$

$182(62.5 \%)$
$29(58.0 \%)$

$133(100 \%)$

Education level

high school

bachelor degree

masters degree

$\mathrm{PhD}$

Occupation

student

non-manual worker

manual worker

unemployed

Marital status

single

married

divorced

Living environment

urban

rural

$$
\begin{gathered}
237(100 \%) \\
141(100 \%) \\
132(100 \%) \\
36(100 \%)
\end{gathered}
$$

$191(100 \%)$

$250(100 \%)$

$25(100 \%)$

$80(100 \%)$

$298(100 \%)$

$226(100 \%)$

$21(100 \%)$

$471(100 \%)$

$75(100 \%)$
$92(56.4 \%)$

$62(60.2 \%)$

$43(70.5 \%)$

$11(78.6 \%)$

$107(59.1 \%)$

$66(71.0 \%)$

$10(62.5 \%)$

$28(54.9 \%)$

$137(58.3 \%)$

$63(70.0 \%)$

$11(68.8 \%)$

$188(64.8 \%)$

$23(45.1 \%)$
$38(23.3 \%)$

$23(22.3 \%)$

$13(21.3 \%)$

$1(7.1 \%)$

$44(24.3 \%)$

$17(18.2 \%)$

$3(18.7 \%)$

$11(21.6 \%)$

$58(24.7 \%)$

$15(16.7 \%)$

$2(12.5 \%)$

$62(21.4 \%)$

$13(25.5 \%)$
Severe depressive symptoms $\mathrm{N}=55$

$28.15 \pm 12.02$

$47(16.2 \%)$

$8(16.0 \%)$

$33(20.3 \%)$

$18(17.5 \%)$

$5(8.2 \%)$

$2(14.3 \%)$

$30(16.6 \%)$

$10(10.8 \%)$

$3(18.7 \%)$

$12(23.5 \%)$

$40(17.0 \%)$

$12(13.3 \%)$

$3(18.7 \%)$

$40(13.8 \%)$

$15(29.4 \%)$
When age was compared between subjects who had moderate to severe depressive symptoms and subjects who didn't have depressive symptoms, a statistical significance was found (median 24.0 vs 26.0; $\mathrm{U}=120666.0$; $\mathrm{p}<0.001$ ). Subjects with moderate to severe depressive symptoms were significantly younger than those who didn't have those symptoms.

Independent predictors for development of moderate to severe depressive symptoms in association with COVID-19 were identified with binary logistic regression and are displayed in Table 3.

\section{DISCUSSION}

To our knowledge based on the search of scientific databases, this is the first study that is assessing fear levels and severity of depression among general population in one of the countries in Europe, during the outbreak of COVID-19. Subjects who reported having fear in association with COVID-19 were likely to be older, single, female, having moderate to severe depressive symptoms, living in urban environments and scored higher on FCV-19S. Fear of losing their life due to the COVID-19 infection was reported among more than half $(53.0 \%)$ of them. On the other hand subjects who tested positive for moderate to severe depressive symptoms were likely to be females, students or either unemployed and younger. More than two thirds $(67.1 \%)$ of subjects associated their moderate to severe depressive symptoms with the current COVID19 outbreak. Having suicidal ideas or self-injuring was reported among $11.2 \%$ of the subjects.

Compared to the initial Ahorsu et al. (2020) study who proposed the FCV-19S which had predominately male sample $(58.0 \%)$, our study sample consisted mostly of females (78.5\%). Subjects in both studies were in similar age group (mean age $(31.25 \pm 12.68)$; $(30.57 \pm 11.26)$ ). Our study also showed that higher scores of FCV-19S were associated with higher levels of fear which was initially proposed and proven by Ahorsu et al. 2020. The other perspective is that subjects who did not experience fear have scored lower on the same scale which indicates the need for further analysis of sensitivity and specificity. Our findings also showed that older individuals had significantly higher levels of fear which could be explained with several theories. Firstly, the studies are showing that SARSCoV-2 is more lethal for older individuals (Jordan et al. 2020, Kobayashi et al. 2020) and thus may lead to increase of fear. The second thing is that fear among older subjects maybe a result of a cohort effect, because either they themselves or their relatives experienced the 1992-1995 war in Bosnia and Herzegovina. Because of the absence of such experience in younger generation, 
fear of a mass threat such as COVID-19 could be less pronounced. Thirdly, studies show that the spreading of the disease is primarily among family members, relatives and friends who intimately contacted with patients, infected carriers (Li et al. 2020) and even with asymptomatic carriers (Yang et al. 2020), so older subjects have not only fear of relatives' disease (Filiptsova et al. 2015) but an increased fear of getting infected. Fear, even though it has its protective effect to decrease the exposure of individuals to the infectious disease (Espinola et al. 2016), is also one of the reason for stigmatization of infected and further spread of the disease among the general population which has already been observed in numerous epidemics (Person et al. 2004, Shultz et al. 2016, Jakovljević et al. 2020) and models (Espinola et al. 2016).

Almost one third $(28.4 \%)$ of the sample presented moderate to severe depressive symptoms and one third (26.1\%) was on watchful list according to PHQ-9 cut off scores. In line with our results, several studies (Kessler \& Bromet 2013, Mutyambizi et al. 2019, Cakici et al. 2017) present the same predictors for development of depressive symptoms among general population. Even though these predictors present general risk factors for development of depressive symptoms, we would like to emphasize the potential role of social isolation which could be one of the contributing factors and has already been shown in a few studies (Matthews et al. 2016, Ge et al. 2017). Moderate to severe depressive symptoms were also associated with fear which was shown in Ahoras et al. 2020 study (Ahorsu et al. 2020).

There are several limitations to our study. Firstly, the subjects who took part in this survey were from general population and we didn't have any information about psychiatric and/or somatic history that could lead to development of either fear of depressive symptoms. A thorough one to one interview is needed in order to establish a diagnosis. The second limitation is the study type. Our study was cross-sectional that makes it difficult to infer causality. The third limitation is that our study may have not reached the vulnerable population due to limited access to internet and internet health resources to those subjects.

\section{CONCLUSION}

In conclusion, based on our findings, fear and depressive symptoms in general population of Bosnia and Herzegovina during the outbreak of COVID-19 were significantly present and they were associated with age, gender, occupation, living environment and they may present a secondary uprising problem connected to outbreak of COVID-19. The findings of this survey should inform service commissioners and decision makers on a need to design preventive measures concerning these risks for mental health of our population in the situation caused by the pandemics of COVID-19.
Acknowledgements: None.

Conflict of interest: None to declare.

\section{Contribution of individual authors:}

Armin Šljivo - study design, data collection, statistical analysis, writing of the manuscript.

Majda Kačamaković - data collection, statistical analysis, writing of the manuscript.

Iman Quraishi - first draft, data collection, coding of the variables.

Alma Džubur-Kulenović - approval of the final version, statistical analysis, manuscript writing.

\section{References}

1. Ahorsu DK, Lin CY, Imani V, Saffari M, Griffiths MD, Pakpour AH: The Fear of COVID-19 Scale: Development and Initial Validation. Int J Ment Health Addict 2020; $1-9$

2. Çakıcı M, Gökçe Ö, Babayiğit A, Çakıcı E, Eş A: Depression: point-prevalence and risk factors in a North Cyprus household adult cross-sectional study. BMC Psychiatry 2017; 17:387

3. covid-19.ba [Internet]: Federalni štab civilne zaštite FBIH. Bosna i Hercegovina. Federacija Bosne i Hercegovine. Naredbe, uredbe i preporuke. [cited 2020 April 12]. Available on: https://covid-19.ba/dokumenti/civilna_zastita [Last accessed: 2020, April 12]

4. Ćosić K, Popović S, Šarlija M, Kesedžić I: Impact of human disasters and COVID-19 pandemic on mental health: potential of digital psychiatry. Psychiatr Danub 2020; 32:25-31

5. Drakulic AM, Radman V: Crisis psychodrama in the era of COVID-19. Psychiatr Danub 2020; 32:22-24

6. Epidemiology Working Group for NCIP Epidemic Response, Chinese Center for Disease Control and Prevention: The epidemiological characteristics of an outbreak of 2019 novel coronavirus diseases (COVID-19) in China. Zhonghua Liu Xing Bing Xue Za Zhi 2020; 41:145-151

7. Espinola M, Shultz JM, Espinel Z, Althouse BM, Cooper $J L$, Baingana $F$, et al.: Fear-related behaviors in situations of mass threat. Disaster Health. 2016; 3:102-111

8. Filiptsova $O V$, Kobets $Y N$, Kobets MN, Timoshyna IA: Population Study of Fears in Two Generations of Ukrainians. Indian J Psychol Med 2015; 37:305-10

9. Ge L, Yap CW, Ong R, Heng BH: Social isolation, loneliness and their relationships with depressive symptoms: $A$ population-based study. PLoS ONE 2017; 12:e0182145

10. Guo YR, Cao QD, Hong ZS, Tan YY, Chen SD, Jin HJ, et al.: The origin, transmission and clinical therapies on coronavirus disease 2019 (COVID-19) outbreak - an update on the status. Mil Med Res 2020; 7:11

11. Huang C, Wang Y, Li X, Ren L, Zhao J, Hu Y, et al.: Clinical features of patients infected with 2019 novel coronavirus in Wuhan, China. Lancet 2020

12. ibm.com [Internet]: SPSS Statistics 20 Available for Download. [cited 2020 April 21]. Available on: https://www.ibm.com/support/pages/spss-statistics-20available-download [Last accessed: 2020, April 21] 
13. Jakovljević M, Bjedov S, Jakšić N, Jakovljević I: COVID19 pandemia and public and global mental health from the perspective of global health security. Psychiatr Danub 2020; 32:6-14

14. Jakovljević M: COVID-19 crisis as a collective hero's journey to better public and global mental health. Psychiatr Danub 2020; 32:3-5

15. Jordan RE, Adab P, Cheng KK: Covid-19: risk factors for severe disease and death. BMJ 2020; 368:m1198

16. Kessler RC, Bromet EJ: The epidemiology of depression across cultures. Annu Rev Public Health. 2013; 34:119-38

17. Kobayashi T, Jung SM, Linton NM, Kinoshita R, Hayashi $K$, Miyama T, et al.: Communicating the Risk of Death from Novel Coronavirus Disease (COVID-19). J Clin Med 2020; 9

18. koronavirususrpskoj.com [Internet]: Vlada republike Srpske. Službena stranica Vlade republike Srpske za pravovremene i tačne informacije o koronavirusu. [cited 2020 April 12]. Available on:

https://koronavirususrpskoj.com/vladine-mjere/ [Last accessed: 2020, April 12]

19. Lai CC, Shih TP, Ko WC, Tang HJ, Hsueh PR: Severe acute respiratory syndrome coronavirus 2 (SARS-CoV-2) and coronavirus disease-2019 (COVID-19): The epidemic and the challenges. Int $J$ Antimicrob Agents 2020; 55:105924

20. Li Q, Guan $X$, Wu P, Wang $X$, Zhou Y, Tong $Y$, et al.: Early Transmission Dynamics in Wuhan, China, of Novel Coronavirus-Infected Pneumonia. N Engl J Med 2020

21. Lin C-Y: Social reaction toward the 2019 novel coronavirus (COVID-19). Social Health and Behavior 2020; 3:1-2

22. Lu X, Zhang L, Du H, Zhang J, Li YY, Qu J, et al.: SARSCoV-2 Infection in Children. N Engl J Med 2020

23. Marčinko D, Jakovljević M, Jakšić N, Bjedov S, Drakulić MA: The importance of psychodynamic approach during COVID-19 pandemic. Psychiatr Danub 2020; 32:15-21

24. Matthews T, Danese A, Wertz J, Odgers CL, Ambler A, Moffitt TE, et al.: Social isolation, loneliness and depres- sion in young adulthood: a behavioural genetic analysis. Soc Psychiatry Psychiatr Epidemiol 2016; 51:339-48

25. Maurer DM, Raymond TJ, Davis BN: Depression: Screening and Diagnosis. Am Fam Physician 2018; 98:508-515

26. Mutyambizi C, Booysen F, Stornes P, Eikemo TA: Subjective social status and inequalities in depressive symptoms: a gender-specific decomposition analysis for South Africa. Int J Equity Health 2019; 18:87

27. Pappas G, Kiriaze IJ, Giannakis P, Falagas ME: Psychosocial consequences of infectious diseases. Clin Microbiol Infect 2009; 15:743-7

28. Person B, Sy F, Holton K, Govert B, Liang A: Fear and stigma: the epidemic within the SARS outbreak. Emerging Infect Dis 2004; 10:358-63

29. phi.rs.ba [Internet]: JZU institut za javno zdravstvo Republike Srpske. Potvrđeni prvi slučajevi virusa korona u Republici Srpskoj. [cited 2020 April 12]. Available on: https://www.phi.rs.ba/index.php?view $=$ clanak\&id $=703$ [Last accessed: 2020, April 12]

30. Shuja HK, Ageel M, Jaffar A, Ahmed A: COVID-19 pandemic and impending global mental healrh implications. Psychiatr Danub 2020; 32:32-35

31. Shultz JM, Althouse BM, Baingana F, Cooper JL, Espinola M, Greene MC, et al.: Fear factor: The unseen perils of the Ebola outbreak. Bull At Sci 2016; 72:304-310

32. Wu Y, Ho W, Huang Y, Jin DY, Li S, Liu SL, et al.: SARS$\mathrm{CoV}-2$ is an appropriate name for the new coronavirus. Lancet 2020; 395:949-950

33. Yang HY, Duan GC: Analysis on the epidemic factors for the Corona Virus Disease. Zhonghua Yu Fang Yi Xue Za Zhi 2020; 54:E021

34. Zu ZY, Jiang $M D$, Xu PP, Chen $W$, Ni $Q Q$, Lu GM, et al.: Coronavirus Disease 2019 (COVID-19): A Perspective from China. Radiology 2020; 200490

35. Zuelke AE, Luck T, Schroeter ML, Witte AV, Hinz A, Engel $C$, et al.: The association between unemployment and depression-Results from the population-based LIFE-adultstudy. J Affect Disord 2018; 235:399-406

Correspondence:

Prof. Alma Džubur Kulenović, MD, PhD

Department of Psychiatry, Clinical Center of University of Sarajevo, University of Sarajevo

Bolnička 25, 71000 Sarajevo, Bosnia and Hercegovina

E-mail:almadzuburkulenovic@yahoo.com 